\title{
AND THE MODERN EPISTEME \\ OF SYMPATHY IN GEORGE ELIOT'S \\ MIDDLEMARCH
}

Volume 46, No. 1, 2020

ISSN 0524-6881 | e-ISSN 1805-0867

https://doi.org/10.5817/BSE2020-1-6

\section{Alberto GABRIELE}

\begin{abstract}
The investment of George Eliot's narrative in characters impersonating the new epistemological concerns of philology (Casaubon) and biology (Lydgate), makes Dorothea's own peculiar vision-in-action guided by sympathy, which brings the novel to a close, despite the hesitant asides of the narrator about her uneven web, a contribution to the modern episteme, an engagement with the modern question of how to encompass the teeming multiplicity of modernity in one binding synthesis. This is done by emplotting the dichotomy fragmentation/unity that runs throughout the novel, and by incorporating many forms of visual representation that project an intuited sense of unity going past fragmentation. The aesthetic polarities explored in the novel are isomorphous with pre-cinematic spectacles: they both offer provisional, fragmented perspectives of parts, while demanding a new rearrangement of these parts on a higher plane. These spectacles, therefore, are not a symptom of a crisis in representation, but rather naturalize, through a long history of self-reflexivity harking back to the late Renaissance, the paradoxical nature of realism.
\end{abstract}

\section{Key words}

Nineteenth-century novel; Victorian; George Eliot; Middlemarch; visual culture; pre-cinema; magic lantern; modern episteme; Michel Foucault

Werner Nekes (1986) and Jonathan Crary (1990), while mapping a rich array of spectacles that shaped vision and the representation of the moving and 3D image since the late Renaissance, have paved the way for a new understanding of the history of vision-in-motion that both questions a teleological narrative leading up to the patented invention of the cinematograph and exceeds an organization of scholarly disciplines in centuries. The technologies enabling multiple forms of vision, such as the phenakistiscope, the thaumatrope, and the flip book build, as Nekes and Crary have remarked, a type of vision that is self-aware of its modality of operation and constructed in the process of vision by the viewers themselves.

These visual spectacles are significant in the history of the modern novel as they become a privileged correlative for novelists who are shaping a new genre that is not tied to any generic categorization: overall, these references to visual phenomena constitute an unacknowledged theory of the novel that dispenses with the traditional notions of the sister arts and of mimesis as inspired by a painterly, static representation. Since psychological processes of visual perception through these new technologies build a subjective view that does not necessarily overlap, in 
the process of vision, with the traditional belief in a static ad frontal perspective, the old model of representation as a "window onto the world," deriving form the Renaissance codification of a perspectival view, is profoundly destabilized. Many nineteenth-century novelists beside George Eliot elaborate sophisticated optical metaphors or mention some of these devices, which were popular forms of entertainment, as well as of public instruction, because they find in them a most apt correlative of the self-reflexive component of literary mimesis: the illusion of reality provided by literature is never an esthetically defined given, but requires the participation not only of the reader who hallucinates the world presented to them, but, in a more self-reflexive fashion, of the authors themselves, who are left with the components of literary illusion in parts - chapters, words, lines of the plot - that they try and spin into motion so as to provide an illusion of temporality to their narratives, as well as to impart a notion of cogency to the whole structure of the novel. Dioramas, panoramas and the oldest magic lantern all contribute to this dispersion of gazes opposed to the centered subject of perspectival vision (Crary 1990). In the relational processing of separate stimuli that these media inspire in the viewers they also undermine the older taxonomic organization of knowledge production of the classical age.

While the new technologies of vision disperse the former centered axis of perception organizing the Southern Renaissance painterly perspectival model, multiplying perspectives and viewing positions, the resulting fragmentation is never entertained and championed as a new esthetics, as it will be the case with the twentieth-century avant-gardes. An insisted discursive formation, instead, deriving from the long tradition of a loosely Platonist model, escapes the unmanageable sensory and cognitive fragmentation provided by the multi sensory experience of industrial modernity to project a sense of unity that coincides, I want to argue, with the esthetic of figurative realism. While aware of the multi-sensory and dispersive experience of modernity, the perception of fragmentation is pushed to the margins of representation, as it challenges the spatial and temporal coordinates of canonical vision. Modern vision through these optical toys is paradoxically fragmented and unitary: it deconstructs a belief in a metaphysical, figurative foundation of reality, following in this artists of the late Renaissance and Baroque period, but -and here is the common trait uniting nineteenth-century pre-cinematic spectacles- it attempts to build, in the process of visualization, a recomposed unity going past the initial impression of fragmentation. Novelists adopt pre-cinematic visual phenomena in their fiction paradoxically, to both question a frontal perspective organizing space, and at the same time to reaffirm, through the power of narrative and literary conventions, the very same classical perspective of a "window view onto the world," which coincides with a reliable model of representation and of knowledge production. Eliot's realism, so sensitive to visual spectacles and to contemporary technologies of vision is not, therefore, similar to the static image of the photograph, which left George Eliot unimpressed, and made her remark somewhat disparagingly that it might rather be an apt description of the work of Dickens. There is a more complex, more fragmented form of reality to account for, which a static contemplation, like photography or painting cannot convey. Since the complex multiplicity of reality yields through the power 
of narrative and the discursive force of figurative realism to a contemplation of a cogent parallel vision next and antithetical to the multidirectional pulls instated by the culture of industrial modernity, I call this vision pre-cinematographic. It shares with the pre-cinematic flip-book logic the self-reflexive awareness of the optical and cognitive move from fragments to a dynamic unity of perception and knowledge construction. Pre-cinematic vision is, therefore, important precisely because some of its modalities of vision fall outside of traditional representation, thus making it a good candidate for the interest that novelists like George Eliot share for these optical toys, through which they attempt to shape a modern realism within and outside of the traditional categories of vision.

An explicit self-reflexive development of the novelistic plot, as well as the insistence on provisional views to be recomposed into a higher unity are not, therefore, antithetical to a discourse of unity; the novel, while highlighting its constituent parts and thus revealing the process of its construction, envisions a form of unity past fragmentation, according to the similar modality of vision - fragmented and cogently complete - that enables pre-cinematographic spectacles. I refer to the pre-cinematic imagination, which entails different degrees of literary mediation, as a way to ascribe to its perceived deconstructive traits a discursive power of reinstating a projected sense of unity. These visual phenomena function, therefore, as an antidote to the claim to an immersive quality of nineteenth-century mimesis, and enable a more subjective, performative creation of the illusion of representation by combining the fragmentary display in the reader's mind of separate chapters, epigraphs, episodes and characters, so as to spin them in an illusionary perception of unity enabling the recognition of a composite and figurative form of realism.

Critics of the Victorian novel at large have drawn parallels between the art of novel writing that offers a vision of reality for the viewer to contemplate and several, specific forms of visual culture that may have inspired it (Witemeyer 1979; Green Lewis 1996; Bryerly 1997; Flint 2000). Ut pictura poesis, the tradition of pictorialism leading back, through Renaissance codifications, to the classical analogy between writing and painting, has been a dominant mode that no doubt mirrored the prestige that the fine arts entertained in the educational curriculum and the appreciation of contemporaries. The higher cultural value that photography gained in the course of the twentieth-century has made it a topic of equally exhaustive attention, reclaiming for the twentieth-century reader the immediate associations that nineteenth-century critics made (sometimes problematizing it) between photography and modernity (Armstrong 1999; Novak 2008), whereas a TV adaptation has been discussed by Lothe (2006). The insistence on visual phenomena in Middlemarch inspired critics like Reva Stump (1959) to carefully chart the visual dynamics of the novel by offering a close-reading of the many instances of seeing that are presented in the narrative. George Eliot's empirical approach to reality has been also analyzed by Barbara Hardy in an essay that focuses on details and the "surface of the novel" (1967). Taking vision as the privileged sense associated from classical antiquity to insight, other critics like Hillis Miller (1974) have investigated the epistemological implications of vision in a text like Middlemarch that grew out of a long and wide-reaching engagement of its author with nineteenth-century theory. 
Pre-cinematic spectacles and studies on optics, however, have not been explored thoroughly in relation to George Eliot's Middlemarch in the essays by Hulme (1967), Hillis Miller (1974; 1975), Jones (1975), although the dialogue between science and literature has been advanced by Beer (1983), Shuttleworth (1984), Kennedy (2010) and, in relation to Middlemarch, with the notion of "empiricist fable" by Hardy (1982) and Carroll (1992). Hugh Witemeyer (1979: 145) does mention that the opening of Felix Holt may be seen as a "dioramic vision," but excludes such a spectacle in his discussion of "the visual arts" in George Eliot. An exception in this tradition is the ground-breaking work of Isobel Armstrong (2008), which finds fascinating parallels between Victorian literature and nineteenth-century visuality, including pre-cinematic spectacles, without mentioning Middlemarch, and Megan Kennedy's (2010: 132), which begins to explore the precinematic in George Eliot, for instance the "tinted glass lenses" in an allusive passage of Adam Bede.

Some of these devices, like the magic lantern, appear in widely discussed passages in Middlemarch - but not for its pre-cinematic qualities -, as they point to the disturbing effect of the Roman vistas on Dorothea's visual faculties during her honeymoon there. This is not the only reference to the magic lantern present in George Eliot's fiction: she mentions pre-cinematic entertainment in other novels, for instance when trying to represent the altered states of consciousness of the clairvoyant protagonist of The Lifted Veil. Pre-cinematic spectacles are interesting precisely because some of them are not cinematic at all, but rather challenge the very tradition of figurative and then photographic representation that gave rise to the cinematograph: while many of these new forms of vision rely on the arrangements of fragmented moments placed in rapid sequence to give the illusion of movement, others insisted on a static vision while relying on bifocal vision to give the impression of a third dimension, like the stereoscope, which reproduced the effects of many older vues d'optrique/peep boxes/mondi novi that 3D cinema attempted to reintroduce. The microscope is another example of an optical instrument that was popularized in the Victorian era through public displays at fairs, but also through its scientific uses. It enabled forms of vision that are filtered by the subjective interpretation of the chaotic products of its vision, a process that Goerge Eliot will reflect upon taking the microscope as an objective correlative of her investigation of reality, which is clearly not cinematic but enables an embodied performance of subjective vision and cognition, leaving to the viewer an agency that the spectator of the patented invention of the cinematograph, particularly when it developed an industry that codified its narrative strategies, lacks.

The nineteenth-century novel, and Middlemarch in particular, is interesting in this history precisely because it absorbs and elaborates suggestions coming from the esthetic of pre-cinematic entertainment, like the relation between fragments and whole, the creation of a parallel vision that problematizes the understanding of reality, the question of subjective and constructed vision. In doing this, both the nineteenth-century novel and the coterminous technology of vision participate, I want to argue, in the theoretical mind-scape, which, according to Michel Foucault, signaled the emergence of the modern episteme (1966). In a novel such as Middlemarch that is so concerned with the question of knowledge-production 
through characters that represent two of the disciplines that epitomize the modern episteme as discussed by Michel Foucault in The Order of Things - philology with Casaubon, and biology with Lydgate - George Eliot adds the cognitive (and political) power of sympathy to build a sense of cogency and unity to her narrative and to the community she imagines. Such a projection of invisible unity is achieved through a sidestepping of the perception of fragments so as to move into an intuited, mystical and pre-cinematic form of unity. Pre-cinematic vision, therefore, when applied to the temporality of making sense of a complex narrative structure, which much belabored the author, enables, in a meta-literary fashion, George Eliot to surpass the literal meaning of words to infuse them with a projected unity of feeling, while advancing a politically committed ethics that is rooted in the contemporary reality of her age.

In order to complicate the understanding of the dynamics between dominant visual discourses and peripheral ones I shall first identify the opposite esthetic of fragmentation vs. reconstructed unity, which are explored and mediated all over the visual landscape of nineteenth-century culture, so as to constitute an esthetic polarity of modernity. ${ }^{1}$ While the idea of unity, cogency and figurative realism can be read through the power of modern technology, in this case the pre-cinematic imagination, I want to argue that technology aimed at a secularized version of a much more complex discursive tradition familiar to all early nineteenth-century authors - and scientists -, but less to our compartmentalized understanding of non-communicating disciplines, i.e. that of a recurrent form of mysticism indebted to the complex heritage of platonism. These two modes, or discursive pulls, coexist, as is common in the composite fabric of any culture, side by side: the intuited realization of an eidetic foundation of reality going past the less structured input of the senses exist next to a scientific enquiry into the purely physiological nature of sight. Our modern notion of specialization, isolating science from other traditions still present in nineteenth-century culture, does not encompass the remaining traces of occult traditions, such as the persistent and often non-critical exploration of mesmerism, that nineteenth-century novelists explored or retraced through other popular forms of occultism. The contested dichotomy visibility/invisibility, tangible matter/metaphysical intuition is not only a productive matrix in nineteenth-century culture that can be identified in many cultural contexts; the very possibility of regaining insight into abstract ideas, thus going past an unmanageable perception of fragmentation, structured also the esthetic conventions of figurative realism irradiating, for instance, from Joshua Reynolds' eighteenth-century lectures at the Royal Academy, in which he extols the Southern Renaissance in opposition to any other more realist and less intuitively abstracted representation of, say, the "boors" of Jacopo da Bassano (ed. 1959: 62). Coleridge, who was an influential voice throughout the nineteenthcentury, echoes Reynolds' views when he states that the perfection of Italian art in opposition to Dutch art lies in its ideal timelessness: "The infant that Raphael's Madonna holds in her arms cannot be guessed of any particular age; it is Humanity in infancy" (1831, ed. 1923:124). ${ }^{2}$ Aiming at excellence of expression by going past the sheer appearance of reality motivates the idea of beauty Reynolds advocates; the final result, in both writing and painting, should demonstrate a "great 
skill in composition" [228]. The realism of the prose writer is dangerously close to the despised genres of the "satirist, epigrammatist, sonneteer, writer of pastorals or descriptive poetry." What disqualifies these genres of poetic expression is precisely what falls outside of the constructed impression of unity, like the transitory remarks of the satirist, the equally unsystematic pointes of the epigrammatist, the randomness of the setting of a pastoral, not to mention the excessive realism of descriptive prose. Highlighting both aspects of this esthetic polarity, without privileging and hypostatizing any of the two, enables to explore a deconstructive component. However peripheral in the dominant esthetic discourses, it will nonetheless be championed by the twentieth-century avant-gardes at a time when the dominant discourse of realism is deeply challenged.

\section{The esthetic polarities of the emerging visual discourse of modernity}

From the opening of Middlemarch, two modes of vision are presented, one analytical and one intuitive, rephrasing the polarity of modernity that I defined above. This twofold mode of vision is exemplified in the opening of the novel by the juxtaposition of two observers, Celia and Dorothea Brooke. While Celia is animated by an analytical approach to reality, Dorothea is often blinded to immediate vision, animated by inner motivation or by intellectual modes of thinking that go beyond sheer observation. In chapter 1 Celia wins Dorothea's evangelical resistance to pomp when she proceeds to open with her the case where their dead mother's jewels are held. Celia is lured by the beauty and social distinction granted by these manufactured jewels. Dorothea, on the other hand, is captured by the physiological perception of colors, but she can only appreciate the precious stones through a filtered mystical contemplation. A mediated kind of perception, introduced by a spiritual echo of Scriptures, allows her to relate them to a higher order of things. "They look like fragments of heaven" [13], she remarks. In this simplistic opposition between the two modes of looking, later complicated by the introduction of other technical devices of vision, lies a concern that runs throughout the novel: immediate vs. intellectualized vision (particularity in relation to the universality of feeling and political action), visible fragments opposed to intellectual categories of knowledge and art.

These two modes, the fragmentary and the contemplative, represent two forms of perception that can be characterized in different degrees oscillating between the opposites of chaotic chance and structured order, multiplicity of perspectives and structured organization of representation. A priority accorded to an empirical recording of impressions structures the former kind of perception; a transcendental attainment of abstract truths the latter. These two modes originate in different epistemological approaches to sensation, unmediated and atomistic in the first case, intellectual and deductive in the second. In this opposition lies the esthetic of what I call the pre-cinematic imagination, not in a literal sense pertaining only to the optical toys that experimented with the possibilities of creating an illusion of movement by juxtaposing fragments in rapid sequence. The novel dramatizes this opposition in the characters of the two sisters: Dorothea's vision 
often fails to see the sheer actuality of the objects in front of her eyes, absorbed as it is by its own mood that transcends immediate reality. Only Celia is able to see the details of Casaubon's attitude, the "corners of his mouth," his blinking before speaking, his unpleasant scrapping of the spoon.

Dorothea's vision is mediated by her interiority, by her own sympathetic motives behind her action, by her love of extremes: "I cannot help believing in glorious things in a blind sort of way" [Chapter 22: 217] she says to Will when dismissing her possible enjoyment of art, since her contemplative mode of vision does not identify with the static representation of the art of painting. For Dorothea, visual and epistemological perceptions are not a question of visible signs, because she transcends them anyway. She admits that she cannot understand painting but she is actively engaged in the art of drawing plans for the construction of better housing for the lower classes. The architect's is a work that imagines ideal spatial perspectives of an unrealized but possible inhabited and animated future, not a work that arranges forms and colors that freeze the flow of life in one static vista. In Dorothea's case, sketching an architectonic project is an expression of potentially kinetic motivation and agency more than an attempt at representing through signs a given subjective and fixed view of reality. This is another instance of the many discursive conjugations of the pre-cinematic imagination, dispersed in several fields without being ascribed only to the material history of visual technologies. Architectonic plans, far from being a sheer two-dimensional sketch, become an animated form guided by personal motivation and political action that mobilizes agencies to build an organic picture of a realized social order. Architectonic plans project Dorothea's keen involvement in social facts and theories, which the ideal imperatives of morals translate into political action. Seeing reality for Dorothea is not different from reading a reported account of historical or social facts. When seeing a spectacle or reading about it, her perception surpasses such accounts and guides her interiority toward the invisible reality of progress. Her vision is the inward vision of intuitive truths governing one's conduct: fragments and partial perspectives build an added, projected reality, in a pre-cinematic manner, a constructed vision that surpasses their individuality.

\section{The pre-cinematic turn: Exploring alternative esthetic modes: The magic lantern}

The pre-cinematic spectacle has a deconstructive force temporarily unmooring a figurative, static representation only to reinstate it on the subjective plane of an embodied and performative type of vision unfolding in the temporality of perception. The technology of pre-cinema enables, therefore, to explore also an alternative esthetic that problematizes a reflective notion of realism. The section of Dorothea's honeymoon is a telling example of a vision problematizing dominant modes of representation, elaborated expanding the deconstructive force inherently present in pre-cinematic spectacles and the embodied performance of vision they require of spectators. During Dorothea's visit in Rome her whole interior system of sympathetic interaction with a loved reality collapses: 
an overcrowding of perception through the incessant stimulation of the fragmentary remains of history weakens her visual faculty. As an early sufferer of the Stendhal syndrome that affected particularly Northern European travelers on the Grand Tour, she is confronted with conflicting views of pagan sensuality and sanctity, with fragmentary remains from unknown centuries, and with disjoined representations. The alienated gaze of the statues, the feeling of "superstition divorced from reverence" [Ch 20: 191], the awe caused by innumerable paintings seen at once poison her feeling for the world that usually blinds her vision of details. Her sympathetic participation to the plights of individuals surrounding her creates a protective filter that colours her vision. Once corruption and chaotic disjunction of elements from various epochs of the eternal city start veiling her gaze, like a red after-retinal image, she cannot but perceive her stay as undermined by a "disease of the retina."

Forms both pale and glowing took possession of her young sense, and fixed themselves in her memory even when she was not thinking of them, preparing strange associations which remained through her after-years. Our moods are apt to bring with them images which succeed each other like the magic-lantern pictures of a doze; and in certain states of dull forlornness Dorothea all her life continued to see the vastness of St Peter's, the huge bronze canopy, the excited intention in the attitudes and garments of prophets and evangelists in the mosaics above, and the red drapery which was being hung for Christmas spreading itself everywhere like a disease of the retina. (181-182)

The vision that will keep on haunting her memory is an ailing vision constructed by the superimposition of particles and details that end up fogging her general perception. The reference to the magic lantern is not here a literal allusion to the technological process that enables the spectacle of the magic lantern, and, possibly, a reflective notion of literary mimesis incorporating the spectacles of the modern age. The spectacle of the magic lantern cannot be defined in a simplistic manner as a projection of images on a screen, the antecedent of the modern slide projection: slides reproducing narrative sequences were projected side by side random images from global destinations of travel and colonial exploitation, and next to slides with in-built optical effects, such as the chromotrope or slides with moving parts. The spectacle of the magic lantern, therefore, alternates between a narrative and structural composition, which it may share with the novel, and the juxtaposed, random spectacles that the culture of modernity may provide, such as perusing a periodical issue or indulging in a contemplative reverie. The sequence of images in a magic lantern show was often tied together by means of a cogent narrative, both implicitly, through the sheer juxtaposition of different images that the reader would learn to read as consequential, and explicitly, through the words of the lanternist that used the images as sheer illustration of the narrative that was being read to the public attending a magic lantern program. Popular novels were adapted to the "big screen" of the lantern show, while original temperance stories targeting a working-class audience with exemplary stories of fallen charac- 
ters on their path to repentance or sobriety incorporated the narrative technique of pamphlets and short stories with titles such as Father Come Home, Shadowed by Sin, and The Way to Heaven for a Sixpence. Magic lantern shows, therefore, helped build a new form of textuality by means and through the fragmented juxtaposition of images and suggestions coming from a variety of sources.

As the passage from Dorothea's honeymoon suggests, the use of the pre-cinematic spectacle of the magic lantern is not in this case a reference to a contemporary spectacle that may help ground literary representation in a reflective theory of literary realism. Other passages, such as the appearance of the "unlit transparency" presented as a symbolic correlative of Dorothea's disenchantment suggest a simply metaphoric use of the pre-cinematic spectacle. ${ }^{3}$ In the passage quoted above, George Eliot does not seem to share the mimetic impulse of the magic lantern to compete with other forms of artistic representation, like painting or photography, whose esthetic principle aimed at a static representation of a frozen moment in time. The mental processes described in the passage have little in common with the stark juxtaposition of different images in a clear sequence. In this passage, like in the passage that compares Bulstrode's memory to the vagaries of a diorama, the visual phenomena alluded to insist on the transitory effects of a blurred vision extending in a temporal continuum. The quote from Middlemarch presents, by contrast, a lifelike quality that is not present in the other references to diorama and unlit transparencies. The first reference, to the diorama, only suggests a rapid sequence of unrelated, individualized spectacles, like in the transitions that would highlight different corners of a diorama. The second one, to the unlit transparencies, points to a disenchanted view of the machinery behind the illusion of mimesis. In Dorothea's perception of the overkill of stimuli offered by the view of Rome, instead, colors and images become a dynamic, superimposed unity of an animated, albeit chaotic, vision. These effects last in Dorothea's memory for a longer period of time than the shorter tricks of dissolving views of the magic lantern or the forms of movement that the lanternist could manually create by shifting focus on different slides or by moving the silhouettes on the glass slide with a lever. What haunts Dorothea throughout her subsequent years is a form of what I want to call the deconstructive force of pre-cinematic spectacle, which is both indebted to the contemporary forms of visual entertainment and a radical challenge to representation founded on the neo-platonist tradition of form, line and color that structured traditional painterly modes of representation. The precinematic spectacle helps explore grey areas of dominant esthetic modalities, while grounding vision in subjective perception, in ways that only experimental art will champion. These explorations of vision and representation, which have remained invisible due to the discursive dominance of figurative realism, while appearing in the explorations of select painters, reemerge only when the latter discourse will be weakened in the context of the early twentieth-century avant-garde.

Classical painting helped establish a view of materiality that contained within itself a path to the metaphysical worlds of platonic ideas, according to the watered down version of platonism that dominated western European culture through the Christian appropriation of some of its motives that influenced also esthetic theory, from Abbot Suger (Panofsky 1957) to Joshua Reynolds. Some of 
the Venetian vistas by Guardi, the elongated figures of El Grieco, the all encompassing background glows of the skies in Claude Lorraine and, more blatantly, the experiments of W.T. Turner, or specific genres such as the watercolor by Carl Blechen or Victor Hugo, represent an alternative to this model. It is not in these predecessors, however, that one should look to find a parallel to George Eliot's experimental vision. It is not in the spectacle of the magic lantern per se, either, that one should look for, as George Eliot does not mention the literal device of the "magic lantern," but rather "the magic lantern picture of a doze," the constructed vision of an altered state of consciousness that becomes a parallel reality with no direct artistic correlative. This visual phenomenon does not rearrange fragments that are to be perceived at rapid intervals in the logical or accumulative sequence of the magic lantern show. In working against the mimetic impulse of artistic (and photographic) representation, the "magic lantern pictures of a doze" signals an important shift to an equally plausible and believable invisibility, however deconstructive it may be at this stage, thus preparing the ground for a reinstatement of order and structure through the power of the other component of the pre-cinematic dialectics, the impulse of ontological order, here represented by the closure of the narrative. The effect on the retina is invisible to all but Dorothea, whose subjective perception grants a trustworthy cogency to her visualization. This subjective trace in Dorothea's consciousness mirrors and anticipates the move, present toward the end of the novel, to a strongly subjective, more focussed, inner vision that dispenses with the realist painterly model. Inner vision resulting from a physiological effect such as a retinal after-image is for George Eliot the ultimate goal of an artistic representation that challenges the painterly model of realism. The same inner vision unifying, in the final part of the novel, all the loose ends in the plot is also a correlative of the moral function ascribed by Eliot to her fiction, that animates reality with a superadded projection of narrative closure. The reality of this equally plausible and invisible projected form will reappear at the end of the novel, transcending the doubts that the narrator disperses, throughout the book, on the workings of knowledge and representation. The structure of the novel insists, in its final sections, on this reconstituted vision of cogency and lifelike verisimilitude requiring a subjective vision to define its status; it dispels both the more abstract and non-representational impulses present in passages such as the lantern picture of a doze, and the doubts that the narrator constantly introduces about the reliability of subjective vision. Dorothea's mode of vision, like many forms of visuality in the novel, has a metaliterary value as an objective correlative of the process of artistic creation and of the figurative drive present in nineteenth-century esthetisc. The dual mode of vision, analytical and constructed, suggests the narrator's interest in the teeming reality that challenges any sense of unity, and at the same time overcomes these transitory impressions in the move towards cogency, a pressing question in the second half of the novel. The awareness of the confluence of scattered atoms to be related in some inevitable connection is filtered by George Eliot in her references to the epicurean, deconstructive treatment of matter as animated by "various entanglements, wights, blows, clashings, motions, by which generally things go on" [275]. ${ }^{4}$ That is what makes the vision in Middlemarch both indebted to 
the dual esthetic of the pre-cinematic polarity and prescient of a more phenomenological exploration of the discontinuities in the perception of space that will reemerge in the modernist period.

\section{The microscope}

A teeming reality as unmanageable as the fragments of history experienced while in Rome, outside of a defined set order to be retraced in separate categories of human interpretation, suddenly reappears through the microscope-lens the narrator employs when moving away from exterior reality into psychological analysis. It is a reality made of hidden motivations and emotional dynamics in constant flux, like the inevitable pairing of Lydgate and Rosamund alluded to through Lucretius' quote, or the hidden predatory scheming of Mrs Cadwallader's matchmaking, which is revealed in its irresistible and dizzying dynamism when a droplet is scrutinized through a microscope (55, discussed also in Wormald 1996 and Armstrong 2002). The zooming-in approach towards the characters' interiority happens through a sudden shift of the narrative ("-but why always Dorothea?," 275) from the outward mien to inner particles of fleeting states of conscience identified and mediated only by new technologies of vision. A whole invisible reality opens up, a whole set of forces and particles are placed under the scientific attention of the narrator. Reality fails to maintain a fixed perspective, that of visible actions and attitudes, and reveals within itself a whole different realm of undetected shifting entities. The multiple realities thus exposed make any approach to reality guided by linear perspective a limited if not illusory one. This new mode of perception grounded in a suddenly increased visual susceptibility highlights the unexpected discovery of an immense and lively parallel reality within a diminutive sample of matter.

The microscope's mode of vision is at first employed by Lydgate as a scientific attempt to describe forms and relations, particles and structures, fragments and webs that a dynamic intuition might relate in a larger system of moving forces. The position of the impersonal narrator that opens chapter 11 ("anyone watching keenly the stealthy convergence of human lots" 88 ), however, can be interpreted as a general metaphor for the narrative activity that traces imaginary links between individual characters outside of the simple registration of the existing structures they inhabit, when perceived at first sight. The analysis of the water droplet under a microscope, which is taken by George Eliot to the intellectual level of a metaphor ("metaphorically speaking"), invests this perceived dynamism, detected at the simplest level of analysis of the physical world, with motivations and intentions to be projected on the novelistic unfolding of the plot.

The microscope functions, therefore, as another form of pre-cinematic spectacle that is both provisionally scattered in fragments and reconstituted in a parallel reality that can be believed to be real by the interpretive observer processing the stimuli deriving form it in a theoretical view. This reality is not precisely like the "magic lantern pictures of a doze," which, in capturing blurry states of consciousness escapes a figurative esthetic representation; microscopic particulars are rather 
an instance of one mode of vision, a fragmentary one, which is parallel to the conventional view appearing to the human eye. Due to its scale, this increased awareness of particulars hinders the vision of the whole, awaiting the intellectual arrangement of details in a larger, theoretical synthesis. In the microscope's view only parts are known. In this sense, the microscope is another metaphor for the artistic representation of psychological realism that opens up the invisible, dynamic world within the characters' apparent motivations and actions. The scientific vision of the microscope enhances the perception of multiple realities and, consequently, creates a multifaceted and dispersive approach to reality that the very structure of the novel reflects. For this reason George Eliot's references to the microscope should not be seen only through the parallel uses of the microscope in a recreative or popularized-scientific context (Lightman 2009), because the literary imagination transforms them, in a pre-cinematic fashion, into a new animated reality that is approached through a performative act of vision and cognition rooted in the temporality of perception.

In the opening of chapter 15 the narrator dismisses Fielding's theatrical asides on poetics and critical reception to focus on "this particular web" of social relations within the Middlemarch community. The narrator's interest does not lie in the confluence of low and high literary traditions that Fielding's novelistic form includes and hypostatizes through narrative devices of old, such as the Greek novel filtered through Renaissance stage adaptations. The very character of a foundling whose social rank is denied at first but then recognized in the process of the novel is not simply a classicist allusion, but a statement of poetics for the new genre of the novel, a foundling on the road with many ancestors and none. The narrator of Middlemarch, soon after correcting Fielding's propositions by privileging a scrupulous analysis of details and relations, signs and structures, introduces a new character, Lydgate, or, rather, starts to scrutinize Lydgate's ambition. It is another shift towards a character's inner world following the earlier sheer mentioning of his name. There is no need to grant a status to the genre of the novel (or of the newly termed "history") in the hierarchic system of the arts, which motivated Fielding's asides. The very act of magnifying a character's inner reality through a focused excursus of the narrative is a bold manifesto of poetics: it stands next to the scientific act of observation through the microscope that structures biological enquiries, or next to the patient comparison and mapping of linguistic and mythological variants that structures the third emergence of philology, the other discipline to be formalized at the site of emergence of what Foucault in The Order of Things, calls the modern episteme. Like other forms of pre-cinematic vision, the microscope presents its point of view as provisional, and subjective, while demanding a new rearrangement of fragmentary takes not in the immediacy of vision, like in the magic lantern or the thaumatrope, but rather in scientific theory. The complexity of the parallel reality unveiled by the microscope is only the first step in a move toward the intellectual vision of scientific theory. Scientific and more popular technologies of vision available to nineteenth-century authors, therefore, denaturalize the identity between sign and referent of the medieval and Renaissance episteme of the analogia entis, defined by the reflection in the empirical world of the stamp of a divine order, through 
an analogy between the macrocosm and the microcosm. An epistemic drive towards order, structure and synthesis surpasses the immediacy of perception that would reinstate a purely epicurean notion of fleeting fragmentariness. This move is formalized through a discursive force that is active in the development of the disciplines of the modern episteme, and at the level of the every-day, in the applications of the research on optics when patenting new devices of vision and representation of movement, and in the forms of vision popularized by the modern novel.

\section{The pre-cinematic impulse of narrative ontology: The uniting power of sympathy}

Lydgate's intellectual effort, as mentioned above, aims at developing further the insights of his predecessors in an anatomical research that would see the organs "as consisting of certain primary webs or tissues, out of which the various organs-brain, heart, lungs, and so on- are compacted" [146]. His effort goes even beyond that first revolutionary insight, willing to detect the "common basis" of these structures, the "homogeneous origin of all the tissues." Lydgate places his research activity as a "link in the chain of discovery" and has the imaginative power to go beyond technological forms of vision, animated as he is by the "Energy" necessary to the production of meaning. Lydgate's vision is an intellectual and intuitive observation ranging from details to unseen patterns, as Celia's and Dorothea's forms of vision taken together are; Lydgate's vision, however, is also a quest for origins in a linear genealogy, like Casaubon's failed search for the "Key to all Mythologies."

The text of the novel itself presents to the reader's expectations of a linear plot a sequence of episodes often fragmentary, often introduced as static tesserae in a mosaic of a small community that represents society at large at a specific time in British history. The novel presents multiple perspectives provided by focused acts of vision, while at the same time developing an arrangement of fragments in a structuring order. Writing, like moral action modelled after St. Theresa's epos, happens, as we read in chapter 10, under "the command of an authority that constrain[s] conscience" [84]. "Order," an insistent keyword recurring more and more toward the end of the novel, self-reflexively highlighting the normative power of narrative (Miller, 1988), is but an arrangement of threads and fragments that are previously observed as scattered throughout the novel. The figure of the fragment, like the Roman ruins, is, thus, the starting point of an observation aiming at universality, a sign among others that intellectual and pre-cinematic vision can arrange in a stable relational structure. The insistence on the need for structure and order is undermined by the very fragments the novel can be broken into: chapters, subjective views, and quotes resist the immediate placement of each in a structure by underlining the provisional fragmented nature of each. The very subtitle of the novel, "a study of provincial life," may hint, as some critics like Hillis Miller have remarked, not so much at a painterly study, as at an experimental analysis, a scientific inquiry. "Study" also suggests a sketch, a provisory 
status of the work, an attempt to provide a pattern of knowledge, a web of relations in a non-definite way. Chaos is a fleeting dynamism of undetermined particles at the root of any modern observation of reality, it uncovers a different reality existing below the level of discursive formations that aim to crystallize it in an ordered form, however relational and dynamic it might be. The many particles resulting from any act of vision are not reduced to the unifying principle of moral good before the end of the novel; fragments can function as a disquieting component undermining intellectual construct. The novel elaborates a constant opposition between fragments of observed reality and the intellectual web of relations that might lead through subjective devotion and ardor to scientific discoveries, epistemological truths, sympathetic interventions in private plights and, in the process, to a new direction in a contemporary literary genre. In the very opening of the appeasing "finale" we read: "For every fragment of a life, however typical, is not the sample of an even web: promises may not be kept, and an ardent outset may be followed by declension; latent powers may find their long-waited opportunity; a past error may urge a grand retrieval" [815]. The very text of the novel reflects the potentiality of elemental forces ("the world is full of hopeful analogies and handsome dubious eggs called possibilities" 81) while at the same time finding a cohesive force to create a possible arrangements of the fragments within a stable structure.

Fragments and webs are opposed and at the same time surpassed. Dorothea's sympathy is the hidden magnetic force going beyond any structural "web" or social network. It is a subjective vision that does not need figurative language to exist, but it nonetheless gives meaning to reality as a condensed subjective vision of cogent action. The theme of sympathy is at first introduced by the narrator's frequent exclamations "Poor Lydgate!," later echoed by different instruments and different tones, like the discordant "poor Harriet," "poor thing," "poor Harriet" again, "poor creature," all in chapter 74. Pity seems to give Middlemarchers a sense of unity, once the social groups close upon themselves after getting rid of Bulstrode who threatened to expose their corruption. It is Dorothea's sympathy, once again blinding her vision, that closes the novel by providing with her feeling directed toward Lydgate, Rosamond and Will a hidden cohesive force beyond any other visible metaphoric elaboration of narrative structure. Dorothea's sympathy has an intuitive value that, again, transcends any detailed analysis of constituents, as well as any traceable direction "scratches" may take in the pattern of a web or of a narrative. Middlemarch pushes the motley and dynamic nature of its vision towards a reassembling of fragments made possible by a visual trick of subjective order. Dorothea is blind to common reality, enthusiasm helps her surpass the experiential into a higher intuition of order. In Dorothea's active sympathy the similar attempts to build order out of fragmentation, represented by the disciplines of biology - through the character of Lydgate - and philology through the character of Casaubon -, are taken to a higher level of unity guided by political principles. They become one through the work of an individual who closes the novel with a positive note rather than with a disillusioned negation of the possibilities of representation and knowledge that deconstructive criticism has insisted upon, as critics like Wormald (1996), Paxman (2003) have argued, 
insisting on different forms of unity, like the "shared community of language" (Shuttleworth 1984: 147).

Scattered elements take shape in the private epos of the home through a female agency, like Dorothea's, that can extend to the public sphere. The challenges of modernity that plague the retina, the unreconcilable multiple realities (visible, intuitive, visible through the microscope, juxtaposed through the "magic lantern pictures of a doze," etc.) are given cogent consistency in human action or in the hope for future human action. The desire for meaning and the invisible psychological processes that give coherence to the world are the counterpart of the experience of fragmented atomism. Dorothea's vision in the novel works in parallel to pre-cinematic vision of thaumatropes, fenakistiscopes and flip-books to construct a visual and intellectual regime where disparate vistas, and individual frames can join in the illusory but trustworthy reality of a cogent union, following a discursive force that is crucial for nineteenth-century culture at large. This union, like the "magic lantern-pictures of a doze" resists a representational esthetic to linger in a flickering movement outside of the traditional boundaries of color and line defining traditional painterly figuration. Dorothea dismisses the fixity of painting, echoing George Eliot's statement in the letter quoted at the opening of this essay: "One must not be unreasonable about portraits. How can a thing which is always the same, be an adequate representation of a living being who is always varying?.” As George Eliot claims in her 1868 essay Notes on Form in Art: "Boundary or outline and visual appearance are modes of Form which in music and poetry can only have a metaphorical presence" [233] where "poetry," she soon after clarifies, is an all-encompassing term that "includ[es] all literary production." The narrative turn in Middlemarch towards an invisible sympathy that has no strict outline in representational terms surpasses all the doubts the narrator casts about the process of interpretation, all the conflicting data from alternative realities (the microscope, magic lantern views, the monuments of history) by transcending them in a parallel reality that puts representation, narrative and vision in motion. This invisible cogency is a constant concern for the mind of the artist (and the reader/viewer) striving to represent the new reality of modernity. Invisibility, therefore, is not an escape from realism but rather an expanded form of realism that highlights the complexity of nineteenth-century reality and points to a wider form of cognition and intellectual knowledge that can register it.

At the end of the century cinema was able to recreate the same ontological cogency challenging the fragmentation of modernity by building a parallel view that stabilizes perception of disappearing fragments onto a screen of projected moving frames. The cinematic image, results from a quantum leap into a higher allegorical reality; it's not the literal meaning of the flesh (of the individual frames) that matters, but the allegorical light cast on the animated world that condenses in the space of the screen, in the letter of the spirit, so to speak. Some pre-cinematic objects operate according to the same stabilizing logic. The psychological and intellectual strategy structuring both cinema and some forms of precinematic vision reinstates in the face of urban fragmentation a form of causality and unity, both of which defined by a cogent sequence of parts, agents, and elements. Narrative consistency and the workings of sympathy in Middlemarch weave 
a web of human plights that stands on equal grounds with the epistemological endeavors of biology and philology. Narrative and agency through individual sympathy create a trustworthy representation of reality; the animated link of sympathy insists on the importance of invisibility and constructed cogency in presenting a reliable vision of the world that can claim to present a participated knowledge of reality. The projected action of sympathy, functioning like an optical device that surpasses its fragmented parts in the creation of a parallel reality, makes possible representation and the belief in the trustworthy vision of the world presented to the reader.

Whereas Foucault in his archeology of the modern episteme chose three disciplines where parts are dynamically related to a whole, i.e. philology, biology and the science of value, George Eliot adds a fourth axis that is more problematic and intuitively more encompassing than the other, more specialized ones. The fourth axis is the idea of personal movement motivated by individual choices based on the politics of sympathy and progress. Movement is not the experiential registering of urban spectacles presented to the eye of the flâneur; movement here has a more crucial importance as the foundational element in a new ontology of fiction held up as a mirror to a (moving) reality. By making the added reality of sympathy an important turning point in the narrative, the novel opens the path to an understanding of the world by means and past the experiential data of reality and perception. Middlemarch invites the reader to empathize with the epos of Dorothea by linking all the loose threads of the plot in a web that is being woven through the faculty of intuition and the theoretical reassembling of parts in a cogent unity.

George Eliot's realism, so sensitive to visual spectacles and contemporary technologies of vision is not, therefore, similar to the static image of the photograph. Since the complex multiplicity of reality yields to the cogent understanding of a parallel vision of intuited unity next and antithetical to the multidirectional pulls of modernity I call this vision pre-cinematographic. It shares with the precinematic "flip book logic" the self-reflexive awareness of the optical and cognitive move from fragments to a dynamic unity performed by the viewers themselves. Pre-cinematic vision is, therefore, important precisely because some of its modalities of vision fall outside of traditional representation, thus making it a good candidate for the interest of novelists like George Eliot who attempted to shape a form of modern realism within and outside of the traditional categories of vision. Self-reflexivity in the novel, the insistence on provisional views is, therefore, not antithetical to a discourse of unity; the novel, while revealing its constituent parts and its construction, envisions a form of unity past fragmentation, according to the similar modality of vision - fragmented and cogently whole - that enables pre-cinematographic spectacles and the intellectual midscale of modern theory.

A novel such as Middlemarch presents both polarities of the esthetic that I have been tracking: the self-reflexive, deconstructive one, which Hillis Miller has underlined, and, at the same time, the more traditional one that grounds narrative in subjective perception, which I relate not only to the pre-cinematic spectacle, but to a widespread discursive formation deriving from platonist sources. This 
esthetic discursive force helps understand the unity of sympathetic feelings that closes the novel. The self-reflective component of the "modern" novel, which deconstructs and questions the very illusion of reality it advances, has a long history, which develops side by side with the history of optical illusions and the experiments in vision since the late Renaissance. In all of these spectacles, the esthetic formulation of what is accepted as a trustworthy representation - for instance in the discourses by Joshua Reynolds at the Royal Academy - manifest the persistence of a loosely platonic esthetic that mediates fragmentation into a higher intuition of order. In the cartesian philosophical tradition, vision enables an unproblematic access to the world outside of the observer through the model of the camera obscura. The perspective of the observer is a static one, opposed frontally to the object of inquiry and built into a visual system of knowledge so seamlessly that opening the eyes into the world coincides with an objective approach to reality. ${ }^{5}$ By contrast, the examples of Northern Renaissance painting (Alpers 1983a, and Striling Maxwell qtd. in Alpers 1983b: 30) point to the appearance of a modern, horizontal axis of a proto-photographic perception free from the constraints of the depth of field filtered through the geometric proportions of a divine order, which is reflected in linear perspective. The complexity of gazes in famous paintings like Velasquez's Las Meninas questions a frontal perspective that arranges volumes along the geometric projections of linear perspective; the painting has been discussed by Foucault as an example of the crisis of traditional representation around the end of the classical age. What Renaissance self-reflexivity suggests, rather than a crisis, is an awareness of the constructed nature of perception. This, in turn, undermines the abstract continuum of time and space of previous models (Rabinbach 1992). These visual experimentations contribute to an esthetic whose discursive underpinnings animate the history of optical toys over a longue durée that cannot be ascribed only to a nineteenth-century context. This history is interesting as it begins to elaborate the "antinomies of realism" (Jameson 2013) pointing to a rich genealogy that cannot be ascribed solely to a nineteenth-century context as Jameson does.

\section{Acknowledgement}

My first public talk on the topic was "Fragmented Vision and the Pre-cinematic Imagination in George Eliot's Middlemarch" at the Nineteenth Century Studies Association 2013 conference held at University of California at Fresno. A podcast of the talk I gave at the University of Melbourne at the opening of the spring semester 2016 has been available since then on the university website at https:// arts.unimelb.edu.au/australian-centre/news-and-events/past-news/macgeorgevisiting-fellow-dr-alberto-gabriele. My deepest thanks to both institutions for their hospitality. 


\section{Notes}

$1 \quad$ See Alberto Gabriele (2016: chapter 5).

$2 \quad$ I am pointing to a broader discursive field which, while finding a loud echo in Coleridge, is in fact more dispersed over a longer period of time. It extends, moreover, beyond the confines of the esthetic conventions of the 'picturesque,' and thus integrates the claim made by James Buzard, following Martin Price (1993: 10).

$3 \quad$ On the transparency see Isobel Armstrong (1996: 123-148).

4 The words have been identified by David Carroll in the Oxford University Press edition as a quotation from Lucretius' De Rerum Natura, I, 633-634.

5 On the evolution of objectivity from an innate structuring modality of knowledge to the modern sense of the word see Lorraine Daston and Peter Galison (2007).

\section{References}

Alpers, Svetlana (1983) The Art of Describing. Dutch Art in the Seventeenth Century. London and Chicago: John Murray and University of Chicago Press.

Alpers, Svetlana (1983)a Interpretation without representation, or, the viewing of Las Meninas (1983) in Representations 1: 30-42.

Armstrong, Isobel (1996) Transparency: towards a poetics of glass in the nineteenth-century. In: Spufford, Francis and Jenny Uglow (eds.) Cultural Babbage. Technology, Time and Invention. London and Boston: Faber and Faber, 123-148.

Armstrong, Isobel (2002) The microscope: mediations of the sub-visible world. In: Luckhurst, Roger and Josephine McDonagh (eds.) Transactions and Encounters. Science and Culture in the Nineteenth Century. Manchester and New York: Manchester University Press, 30-54.

Armstrong, Isobel (2008) Victorian Glassworlds. Glass Culture and the Imagination, 18301880. Oxford and New York: Oxford University Press.

Armstrong, Nancy (1999) Fiction in the Age of Photography: the Legacy of British Realism. Cambridge, Mass: Harvard University Press.

Beer, Gillian (2009) [1983]. Darwin's Plots. Evolutionary Narrative in Darwin, George Eliot and Nineteenth-Century Fiction. Cambridge and New York: Cambridge University Press.

Buckley, J. H. (ed.) (1975) The Worlds of Victorian Fiction. Cambridge, Mass: Harvard University Press.

Buzard, James (1993) The Beaten Track. European Tourism, Literature, and the Ways to Culture, 1800-1918 Oxford: Clarendon Press.

Byerly, Alison (1997) Realism, Representation, and the Arts in Nineteenth-Century Literature. Cambridge and New York: Cambridge University Press.

Carroll, David (1992) George Eliot and the Conflict of Interpretations. A Reading of Her Novels. Cambridge and London: Cambridge University Press.

Coleridge, Samuel Taylor (1923) Table Talk and Omniana. London, G Bell and Sons.

Crary, Jonathan (1990) Techniques of the Observer. On Vision and Modernity in the $19^{\text {th }}$ Century. Cambridge, Mass and London, England: MIT Press.

Daston, Lorraine and Peter Galison (2007). Objectivity. New York: Zone Books.

Eliot, George (1996) Middlemarch, a Study of Provincial Life. Oxford and New York: Oxford University Press.

Eliot, George (1990) Selected Essays, Poems and Other Writings. Edited by A. S. Byatt and Nicholas Warren. London and New York: Penguin Books.

Eliot, George The Lifted Veil. Project Gutemberg. http:/ / www.gutenberg.org/ebooks/2165. Accessed February 2, 2018. 
Eliot, George (1932) The Mill on the Floss. Leipzig: Tauchnitz.

Flint, Kate (2000) The Victorians and the Visual Imagination. Cambridge: Cambridge University Press.

Foucault, Michel (1994) [1966] The Order of Things. An Archeology of the Human Sciences. New York: Vintage.

Green-Lewis, Jennifer (1996) Framing the Victorians. Photography and the Culture of Realism. Ithaca and London: Cornell University Press.

Hardy, Barbara (1967) (ed.) Middlemarch. Critical Approaches to the Novel. London: Athlone Press.

Hardy, Barbara (1982) Particularities. Readings in George Eliot. London: Peter Owen.

Hillis Miller, J. (1974) Narrative and history. ELH 41(3), 444-474.

Hillis Miller, J. (1975) Optic and semiotic in Middlemarch. In: Buckley, J. H. (ed.) (1975) The Worlds of Victorian Fiction. Cambridge, Mass: Harvard University Press, 124-145.

Hillis Miller, J. (2006) A Conclusion in which almost nothing is concluded'. In: Chase, Karen (ed.) Middlemarch in the Twenty-First Century, Oxford and New York: Oxford University Press, 133-156.

Hulme, Hilda M (1967) The language of the novel. Imagery. In: Hardy B. Middlemarch. Critical Approaches to the Novel. London: Athlone Press, 87-124.

Jameson, Frederic (2013) The Antinomies of Realism. London and Brooklyn: Verso.

Jones, D. J. (2011) Textualities, Pre-cinematic Media and Film in Popular Visual Culture 16701910. Cardiff: University of Wales Press.

Kennedy, Meegan (2010) Revising the Clinic. Vision and Representation in Victorian Medical Narrative and the Novel. Columbus, Ohio: Ohio State University.

Lightman, Bernard (2009) Victorian Popularizers of Science: Designing Nature for New Audiences. Chicago: Chicago University Press.

Lothe, Jacob (2006) Narrative Vision in Middlemarch. The Novel Compared with the BBC Television Adaptation in Chase Karen (ed.) Middlemarch in the Twenty-First Century, Oxford and New York: Oxford University Press, 177-199.

Nekes, Werner (1986) Film Before Film. Documentary. Filmförderung Nordrhein-Westfalen.

Novak, Daniel A. (2008) Realism, Photography, and Nineteenth-Century Fiction. Cambridge and New York: Cambridge University Press.

Panofsky, Erwin (1957) Gothic Architecture and Scholasticism. Meridian Books.

Paxman, David (2003) Metaphor and knowledge in Middlemarch in Metaphor and Symbol 18(2), 107-123.

Rabinbach, Anson (1992) [1990] The Human Motor. Energy, Fatigue, and the Origins of Modernity. Berkeley and Los Angeles: University of California Press.

Reynolds, Joshua (1959) Discourses on Art. San Marino, Cal.: Huntington Library.

Shuttleworth, Sally (1984) George Eliot and Nineteenth-Century Science. Cambridge and London: Cambridge University Press.

Stump, Reva (1959) Movement and Vision in George Eliot's Novels. New York: Rissell \& Russell.

Witemeyer, Hugh (1979) George Eliot and the Visual Arts. New Haven and London: Yale University Press.

Wormald, M. (1996) Microscopy and semiotic in Middlemarch. Nineteenth-Century Literature 50(4): 501-524.

Alberto Gabriele, Ph.D. and Habil. Prof. as Associate Professor, is the author of three monographs: Reading Popular Culture in Victorian Print: Belgravia and Sensationalism, The Emergence of Pre-cinema: Print Culture and the Optical Toy of the Literary Imagination and of the forthcoming The Nineteenth-Century Novel and the Precinematic Imagination: Fragmentation, Movement and the Modern Episteme. A recipient of a Fulbright (New York University), 
a Macgeorge fellowship (University of Melbourne), Gladstone's Library residency fellowship (Howardeen, UK) and one from the Institute for the History of the Production of Knowledge (New York University), he also edited the collection of essays: Sensationalism and the Genealogy of Modernity: a Global Nineteenth-Century Approach. He is currently working, while teaching at the University of Cassino, Italy, on a fourth book on the nineteenthcentury book industry, excerpts of which have appeared in Book History, Memoires du Livre/ Studies in Book Culture and in the forthcoming issue of the Internationales Archiv für Sozialgeschichte der deutschen Literatur.

Address: Alberto Gabriele, Università degli Studi di Cassino, Department of Foreign Languages and Literatures, Via S. Angelo, loc. Folcara, room no. 202, 03043 Cassino (FR), Italy. [e-mail: ag356@nyu.edu] 